\title{
A interação dos relacionamentos com os recursos e a legitimidade no processo de criação de uma organização social
}

\section{The interaction between relationships, resources and legitimacy in the process of creating a social organization}

\author{
Luaiano Rossoni ${ }^{1}$ \\ Rivanda Meira Teixeira
}

\section{Resumo}

Os estudos sobre empreendedorismo são normalmente fragmentados, com diversos enfoques de análise e pressupostos epistemológicos e ontológicos distintos. No entantojá existem esforços de alguns autores em analisar tal fenômeno por meio de uma perspectiva mais integradora. Nessa perspectiva, o objetivo do presente estudo é analisar como os fundadores da ONG Aliança Empreendedora utilizaram a sua rede de relações no sentido de conseguir recursos e legitimidade para a criação da referida organização. Como base teórica, três abordagens foram adotadas: rede de relações, visão baseada em recursos e legitimidade. Recorreu-se à estratégia de estudo de caso, por meio da triangulação de diversas fontes de evidências, com o objetivo de entender como se deu a interação da rede de relações com os reaursos e a legitimidade no processo de criação dessa organização social. Verificou-se a existênaia de consistêncianas abordagens teóricas adotadas no estudo, o quelevau arefletir sobre a necessidade de compreensão da criação de novos negócios pelo enfoque no contexto, e não apenas no empreendedor.

Pala vras-chave: empreendedorismo; estudo de caso; legitimidade; recur sos; relações.

\section{Abstract}

Studies on entrepreneurship are usually fragmented, with several focuses of analysis and different epistemological and ontological foundations. However, efforts already exist on the part of some authors in analyzing such phenomenon through a more integrated perspective. The objective of the present study is to analyze how the founders of Aliança Empreendedora (a non-governmental organization) used their relationship network to get resources and legitimacy for the creation of the referred organization. Three theoretical approaches were adopted: relationship networks, vision based on resources and legitimacy. The strategy of case study was adopted and a triangulation of several sources of evidences was made in order to understand the interaction between the relation ship networks and the resources, as well as the legitimacy in the process of creation of this social organization. Consistency between the theoretical approaches adopted in the study was reached, which has led to the reflection about the necessity of focusing not only the entrepreneur in order to comprehend the creation of new business, but also the context.

Keywords: entrepreneurship; case study research; legitimacy; resources; relationship networks.

\footnotetext{
1 Mestre e doutorando em administração pela Universidade Federal do Paraná. Professor-pesquisador do Programa de Mestrado e Doutorado em Administração - PMDA da Universida de Positivo e Pesquisa dor do Centro de Pesquisa e Pós-Gra dua ção em Administração - CEPPAD da Universida de Federal do Paraná - UFPR. Endereço: Rua Osmário de Lima,598 - Capão da Imbuia - Curitiba/Paraná - Bra sil - CEP: 82810260 . Email:Irossoni@gmail.com.

2 Doutora em Administração pela Cranfield University, Inglaterra. Professora da Universidade Federal do Paraná - UFPR. Endereço: Rua General Carneiro 885, apto 701 - Centro - Curitiba/Paraná - Brasil - CEP: 80060150.E-mail: rivanda teixeira@terra.com.br

Artigo submetido em maio de 2007 e aceito em fevereiro de 2008
} 


\section{Introdução}

Os estudos sobre empreendedorismo normalmente são fragmentados, apresentam enfoques diversos de análise e pressupostos epistemológicos e ontológicos distintos. Alguns desses estudos concentram-se isoladamente no empreendedor em si; outros nas organizações, ou no contexto, ou no processo. Entretanto, devido à complexidade do assunto, alguns pesquisadores atêm-se à análise do empreendedorismo em sua totalidade (DANJOU, 2002; GART NER, 1985; PAIVA JÚNIOR; MELLO; GONÇALVES, 2005; VERSTRAETE, 1999). Seguindo essa corrente, pretende-se, neste artigo, avançar no ent endimento sobre o empreendedor como fenômeno relacional, que usa suas relações para adquirir legitimidade e recursos. Desse modo o objetivo é apresentar como os fundadores da ONG Aliança Empreendedora utilizaram a sua rede de relações para conseguir legit imidade e recursos para a criação da organização.

Para tanto, inicialmente será apresentada uma breve revisão bibliográfica a respeito das redes de relações, visão baseada em recursos, legitimidade e seus respectivos usos no campo de empreendedorismo e de criação de novos negócios. Num segundo momento, será ilustrado o arcabouço analítico utilizado no estudo, que abrange o empreendedor e sua rede de relações na busca por legitimidade e recursos. Depois, serão descritos os procedimentos metodológicos e analíticos empregados no presente estudo de caso. Em seguida, haverá a caracterização e o relato histórico da formação da ONG. Por fim, examinam-se os dados mediante a utilização do quadro de análise exposto na metodologia, com algumas considerações finais, levantando questões sobre a generalidade analítica do arcabouço proposto e respondendo à seguinte questão de pesquisa: como o empreendedor utiliza sua rede de relações para angariar legitimidade e recursos para a construção de um empreendimento?

\section{Empreendedorismo e rede de relações}

É possível verificar, no campo do empreendedorismo, diferentes concepções sobre o tema. Seus múltiplos componentes vêm sendo observados e analisados por economistas, sociólogos, historiadores, psicólogos, especialistas de ciências do comportamento ou de gestão (BRUYAT; JULIEN, 2001; FILION, 1999). Sendo assim, as definições de empreendedor e de empreendedorismo, segundo Filion (1999), baseiam-se nas premissas de cada área do conhecimento - há predomínio, na grande maioria dos estudos, de definições de economistas como Cantillon (1755), Say (1816, 1964) Schumpeter (1934), Vérin (1982), de sociólogos como Weber (1930) e comportamentalistas, por exemplo, Kets de Vries (1985), Lorrain e Dussault (1988), McClelland(1961, 1971) Timmons (1971).

Existem várias outras tentativas de se classificar o fenômeno do empreendedorismo - no entanto ainda incompletas. Apesar disso, o fenômeno empreendedor começa a ser avaliado de forma multidimensional (DANJOU, 2002; GART NER, 1985; PAIVA JÚNIOR; MELLO; GONÇALVES, 2005; VERSTRAETE, 1999). Segundo Verstraete (1999), o empreendedorismo é um fenômeno psicossocioeconômico e cultural complexo; portanto, a utilização do conceito multidimensional da ação empreendedora, que envolve o empreendedor, a empresa, o ambiente e o processo, atuando de forma dialógica, justifica-se por representar um ponto de vista mais amplo. Guimarães (2004) destaca que o recente surgimento de uma visão multidimensional do empreendedorismo relaciona-se, aparentemente, com a também recente influência de outros paradigmas epistemológicos, além dos racionalistas, funcionalistas e positivistas, pois hoje há crescente presença de trabalhos que seguem a corrente dialética, construcionista, cibernética e da complexidade. Nesse contexto, vários elementos, além do empreendedor como unidade de análise, são relevantes à construção do conhecimento sobre o assunto. Assim, almeja-se, aqui, resgatar elementos teórico-empíricos em estudos sobre rede de relações, recursos e legitimidade, que possam contribuir para a construção de um arcabouço analítico que abranja, pelo menos em parte, a complexidade do assunto.

A rede de relações, ou redes sociais, pode ser vista como padrão genérico de troca (BURT, 1992; NOHRIA, 1992), estruturado com base na definição de papéis, atribuições e relações entre seus atores. Burt (1992) ressalta as vantagens da rede na propagação de informações, na aquisição de recursos e na possibilidade de 
conseguir vantagens. O autor afirma que o benefício de um relacionamento se determina pelo tempo e energia investidbs para desenvolvê-lo e mantê-lo. Dessa forma, atores individuais ganham prestígio e influência não só por meio de sua posição na rede, mastambém pela energia que despendem nesses relacionamentos.

Nessa mesma lógica, empreendedores podem ser vistos como atores sociais que usufruem os benefícios de seus relacionamentos. Filion $(1991,1993)$ afirma que, aparentemente, o sistema de relações é o principal elemento de suporte para a evolução de uma visão de negócio. Para o autor, o estabelecimento de relações influencia diretamente a qualidade da visão de negócio do empreendedor, contribuindo para uma maior assertividade de suas ações. Estas requerem, por sua vez, novas relações e, conseqüentemente, novas visões de negócio. Filion (1991, 1993) identificou três tipos de relações, como podem ser vistas no Quadro 1.

\section{Quadro 1 - Os três níveis de relações}

\begin{tabular}{ll}
\hline \multirow{2}{*}{ Primário } & Familiares. \\
\cline { 2 - 2 } Secundário & Ligações em torno de mais de uma atividade. \\
\cline { 2 - 2 } Terciário & Ligação em torno de uma atividade bem determinada. \\
\hline & Cursos. \\
\hline & Livros, viagens, feiras e exposições industriais. \\
\hline
\end{tabular}

As relações primárias são as que envolvem pessoas próximas do empreendedor. Normalmente são os membros da família ou amigos mais próximos com quem ele mantém vínculos variados: afetivos, intelectuais, esportivos, recreativos, entre outros. Essas relações são as mais influentes no que se refere ao conjunto de crenças e valores do empreendedor - elas influenciarão as escolhas que ele fará, em outros níveis de sistema de relações. Já as secundárias se desenvolvem por meio de atividades bem definidas, como clubes sociais, grupos religiosos, negócios e política. Algumas destas até se podem tomar relações primárias. Por fim, as terciárias satisfazem uma necessidade bem definida, implicandb, não necessariamente, contato pessoal, mas também com áreas de interesse, como cursos, viagens, eventos, livros, entre outros (FLION, 1991). Para o autor, a at enção dedicada ao gerenciamento das relações parece const it uir um dos principais elementos que permitem ao empreendedor formar uma visão de negócio coerente; assim, as relações são um fator crucial para seu desenvolvimento.

Segundo Filion (1991), o empreendedor que tem uma visão, mas não desenvolve um sistema de relações, pode correr o risco de ser considerado um sonhador ou de não progredir no desenvolvimento do negócio. Portanto, buscar aconselhamento por meio de redes de contatos (BRUSH; GREENE; HART, 2002) é primordial para que o empreendedor diminua o risco de insucesso. Diante disso, Paiva Júnior, Mello e Gonçalves (2005) afirmam que a ação social do empreendedor se fortalece a partir das relações institucionalizadas sob a marca da confiança e da adaptabilidade.

\section{Empreendedorismo e recursos}

Muitos estudos sobre estratégia sugerem que uma base de recursos, reunidbs de uma forma única, geram vantagens competitivas que levam à criação de valor (WERNERFELT, 1984). Desde Penrose (1959), a visão baseada em recursos tem estado presente nos estudos sobre estratégia. Tal abordagem ganhou ênfase a partir dos anos 80 (WERNERFELT, 1984) e, principalmente nos anos 90 (BARNEY, 1991, 1996; COLLIS; MONTGOMERY, 1995; GRANT, 1991), quando, então, no foco da análise organizacional estão os recursos internos das organizações. Desse modo, a acumulação, a seleção e a aplicação de recursos são entendidas como função da tomada de decisão de âmbito interno da organização. Os fatores extemos não são negados (OLIVER, 1997), mas entendidos como passíveis de análise objetiva, sujeitos à escolha racional (CRUBELLATE; PASCUCCI; GRAVE, 2005). A firma é vista como um pacote de recursos únicos (SPANOS; LIOUKAS, 2001), e com base nestes se constitui uma variedade de opções que representará a sua área de competência (FOSS, 1997). 
Para Barney (1991), recursos de firma referem-se a domínios, capacidades, processos, informações e conhecimentos organizacionais controlados por uma firma, que possibilitam a esta conceber e implementar estratégias que melhorem a eficiência e a eficácia. Das diversas classificações de tipos de recursos disponíveis na literatura, há consenso em tipificá-los em tangíveis e intangíveis (CHATTERJEE; WERNERFELT 1991; COLLIS; MONT GOMERY, 1995; WERNEFELT, 1984). Ordenando a tipificação de diversos aut ores, Collis e Montgomery (1995) classificaram os recursos em três tipos: (a) at ivos tangíveis - recursos financeiros e bens físicos, como propriedades, estoques, equipamentos; (b) ativos intangíveis - vantagens ou talentos que incluem propriedade intelectual; podem ser internos, como fórmulas, rotinas, cultura organizacional e know how; ou externos, como marcas, pat entes, contatos comerciais e reputação; (c) capacidades organizacionais - a junção dos ativos tangíveis e intangíveis, possibilitando o desenvolvimento de tarefas e rotinas únicas que, segundo Amit e Schoemaker (1993), resume-se na habilidade da firma em explorar e combinar recursos de forma diferenciada.

Os estudos sobre empreendedorismo se concentram nas atividades iniciais e de crescimento, e reconhecem a importância dos recursos que devem ser adquiridos para se iniciar um empreendimento (BRUSH; GREENE; HART, 2002; SHANE; VENKAT ARAMAN, 2000). Nestes casos, o primeiro recurso é o empreendedor (VENKAT ARAMAN, 1997), que busca organizar os recursos necessários para dada oportunidade (ALVAREZ; BUSENITZ, 2001). Assim, o desenvolvimento de um empreendimento é seqüencial, apresenta dificuldades peculiares, exigindo tarefas específicas em cada fase (BRUSH; GREENE; HART, 2002). No entanto raramente se considera, na literatura, o processo de construir, a partir do zero, uma base de recursos. Chandler e Hanks (1994) sugerem que se dê mais at enção aos estudos sobre a construção de bases de recursos das empresas iniciantes. Preenchendo essa lacuna, Brush, Greene e Hart (2002) buscam determinar quais são as decisões referentes aos recursos, e em que ordem tais decisões são tomadas pelos empreendedores.

Os autores classificam os recursos em seis tipos: humano, social, financeiro, físico, tecnológico e organizacional. Cada tipo tem diferentes dimensões, de acordo com a escala de complexidade. Recursos simples são tangíveis, descontínuos e baseados na propriedade; já os complexos são intangíveis, sistemáticos e baseados no conhecimento (AMIT; SHOEMAKER, 1993; PENROSE, 1959). Apesar dessas classificações, Brush, Greene e Hart (2002) propõem uma segunda forma de analisar a criação e o desenvolvimento de um negócio, por meio de uma 'pirâmide de recursos'. Como exposto na Figura 1, na base da pirâmide estão os recursos genéricos, mais fáceis de serem adquiridos. A partir do momento em que estes são combinados, se tomam capacidades que aumentam a habilidade da empresa em aplicar recursos e atingir seus objetivos (AMIT; SHOEMAKER, 1993). Quando as capacidades tornam-se cruciais para a missão da empresa e são executadas de maneira consistente, passam a ser competências essenciais. O conjunto de competências essenciais especializadas, que permite à empresa sobressair-se em relação às outras, se toma ativos estratégicos (AMIT; SHOEMAKER, 1993). Quando estes são valiosos, raros, não imitáveis e insubstituíveis, se const ituem em uma vantagem única ao empreendimento (BARNEY, 1991, 1996). 
Figura 1 - Pirâmide dos recursos para criação de valor

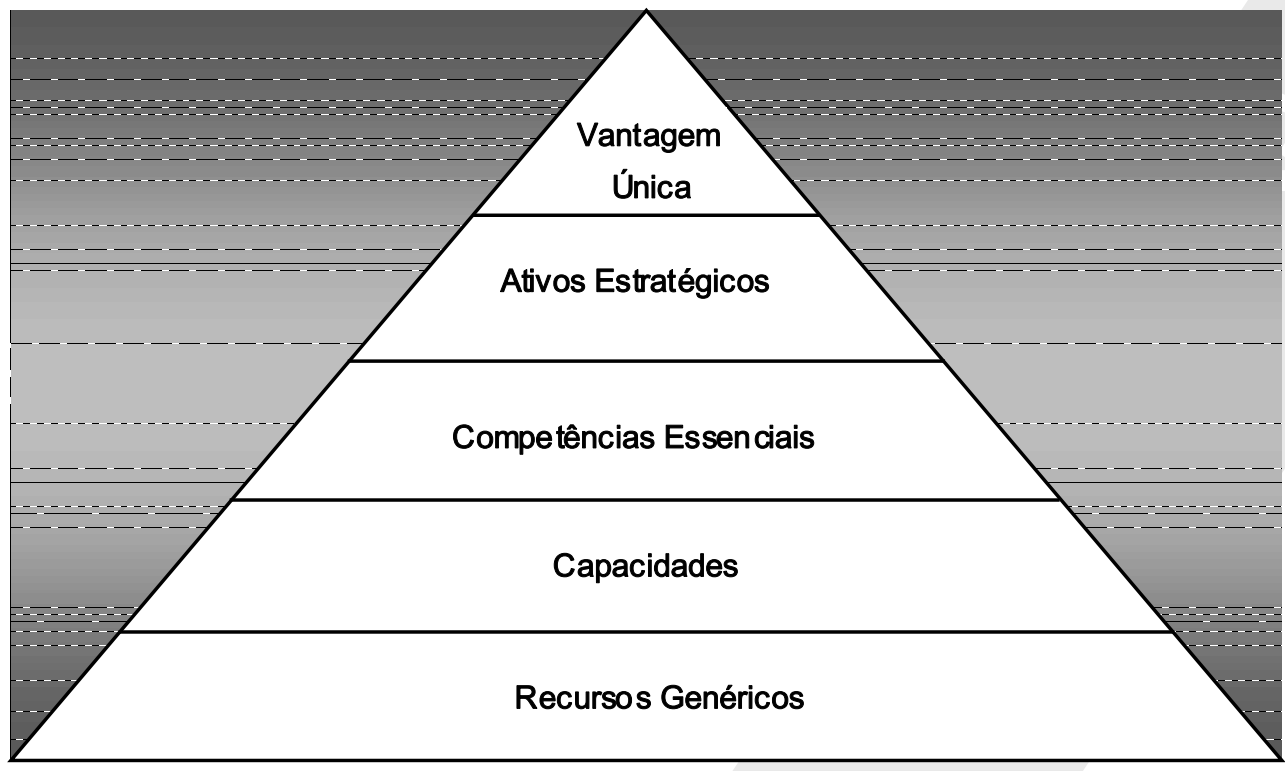

Fonte: Adaptado de Brush, Greene e Hart (2002).

Organizações nascentes podem variar em relação à fase em que estão no desenvolvimento da pirâmide. Algumas começam somente com o mínimo de recursos genéricos; outras com capacidades e competências essenciais desenvolvidas. Porém, segundo Brush, Greene e Hart (2002), a maioria dos empreendedores começa seus negócios com capital humano e social, que foi desenvolvido em outras empresas; assim, alavancam tais recursos parar adquirir outros. Todavia conseguir recursos não é fácil - tal tarefa constitui-se um desafio. Para Brush, Greene e Hart (2002), os empreendedores enfrentam quatro tipos de desafios detalhados nos parágrafos seguintes, a saber: reunião, atração, combinação dos vários recursos e transformação de recursos individuais em recursos organizacionais.

1) Reunião de recursos. O empreendedor começa com recursos individuais (formação acadêmica, experiência, reputação, conhecimento do setor, contatos) seu processo de construção de base de recursos. Nos estágios iniciais, os empreendedores enfrentam decisões relativas a seqüência, prazo e tipos de recursos que devem captar para o novo negócio. Porém, a escolha de quais recursos são mais ou menos importantes ao novo empreendimento vem da interpretação de quanto representam para eles (ALVAREZ; BUSENIT Z, 2001).

2) Atração de recursos. Em muitos casos, devido à falta de reputação e de um histórico de resultados, empreendedores têm grande dificuldade em atrair recursos. Eles utilizam os artefatos (plano de negócios, instalações sofisticadas, entre outros) para criar uma imagem de sucesso que lhes dê legitimidade em face dos investidbres, fomecedores, consumidores e outros envolvidos no processo. Nesse caso o discurso do empreendedor desenvolve papel fundamental na obtenção de recursos (LOUNSBURY; GLYNN, 2001). Conforme Bamey e Hansen (1994), a confiança pode ser origem de vantagem competitiva, em algumas situações, para as organizações. Muitas vezes a confiança que a rede de relações deposita no empreendedor é a sua única fonte de atração de recursos.

3) Combinação de recursos. A combinação dos recursos básicos no novo empreendimento afeta o desenvolvimento futuro da base de recursos. Os empreendedores trazem diferentes crenças para suas organizações sobre o valor atribuído aos recursos e ao seu potencial de combinação e transformação em algo de valor (SHANE; VENKAT ARAMAN, 2000). Essas crenças podem provir deste elenco: experiências individuais, formação acadêmica, redes sociais, capital financeiro ou de variações cognitivas na habilidade do empreendedor em trabalhar com conceitos e informações em novas idéias (ALVAREZ; BUSENITZ, 2001; BRUSH; GREENE; HART, 2002). Aparentemente, a rede de relações do empreendedor tem papel 
fundamental nessa fase de combinação de recursos, pois esta facilita o aprendizado e dá suporte ao desenvolvimento do empreendimento (BRUSH; GREENE; HART, 2002; FILION, 1993).

4) Transformação de recursos individuais em recursos organizacionais. Empreendedores devem ir além de reunir, atrair e combinar recursos para terem sucesso. Seus conhecimentos e habilidades devem ser institucionalizados, fomecendo a base do crescimento de valor do conjunto de recursos (ARBAUGH; CAMP; VORHIES, 1999). Nesse caso, a habilidade do empreendedor em transferir suas competências individuais para o negócio é essencial ao desenvolvimento do lastro de recursos do empreendimento. Ou seja, empreendimentos que não apresentam condições de possibilitar a transição de recursos individuais do empreendedor para recursos organizacionais terão sérias restrições de crescimento.

Tradicionalmente na área de empreendedorismo, a decisão sobre seleção, utilização e acumulação de recursos caracteriza-se por uma escolha economicamente racional, condicionada por limites de informação, bases cognitivas e ambigüidade causal (AMIT; SCHOEMAKER, 1993). Entretanto, por meio de tal visão, em particular, não se examina o contexto social, em que a decisão de seleção de recursos está imersa (OLIVER, 1997). Diante dessa limitação, outras recentes abordagens vêm desenvolvendo maneiras altemativas de se compreender a capacidade humana de empreender, principalmente as que se contrapõem aos pressupostos da escolha racional. Algumas destas integram a visão baseada em recursos com a perspectiva institucional, focando-se na legitimidade como aspecto central no desenvolvimento do empreendimento, o que possibilita analisar o fenômeno do empreendedorismo além de uma abordagem racional-econômica.

\section{Empreendedorismo e legitimidade}

Um empreendedor, aqui visto como agente, decide de acordo com suas referências sociais, ou seja, é condicionado por crenças, normas e valores socialmente construídos (GRANOVETTER, 1985). Tal condicionamento pode ser entendido como determinismo em contraponto à perspectiva atomista da escolha racional. Diante dessa divergência, institucionalização e decisão estratégica foram vistas como fenômenos opostos durante muito tempo. Apesar disso, existem alguns pontos integradores. Segundo Scott (2001), as organizações necessitam não apenas de recursos materiais e informação técnica para sobreviver, mas, de conformidade às expectativas sociais; visto que contribui para a sobrevivência e para o sucesso empresarial. Nesse sentido, se faz necessário entender o fenômeno da legitimidade e sua íntima dependência ao processo de interpret ação e construção de significado (CRUBELLATE;PASCUCCI; GRA VE, 2005).

Para Suchman (1995, p. 574), "legitimidade é a percepção ou pressuposição generalizada de que as ações de uma entidade são desejáveis ou apropriadas dentro de algum sistema socialmente construído de normas, valores, crenças e definições”. O autor vê duas formas de como a legit imidade vem sendo trabalhada nas teorias organizacionais. A primeira como um fator estratégico que as organizações podem manipular instrumentalmente com o objet ivo de obter suporte social e acesso a recursos. Nesse caso, a legitimidade é vista também como recurso que se pode buscar e planejar intencionalmente. Já na segunda, considera-se a legitimidade proveniente da dinâmica estruturante dos setores sociais mais amplos - fora do escopo do controle de qualquer indivíduo ou organização -, sendo 'dada' pela conformidade social da organização. Segundo Crubellate, Pascucci e Grave (2005), o problema dessa divisão está em reproduzir uma visão dicotômica da legit imidade como elemento ora fort emente estruturado, ora com grande influência da agência, não permit indo a explicação de como a agência estratégica e as estruturas sociais se relacionam.

Diante dessas limit ações impostas por tais visões dicotômicas, começam a surgir algumas abordagens de cunho multiparadigmático que tentam conciliar agência e estrutura; escolha racional e limitação dos padrões institucionais (DIMAGGIO, 1988; GIDDENS, 1989; SCOTT, 2001). Com tal visão permitiu-se enxergar estrutura e ação como recursivas, em que a ação não é só limitada pela estrutura institucionalizada, mas também por ela possibilitada.

Contudo, mesmo em contextos ambientais altamente institucionalizados, vem-se demonstrando que existe, por parte dos indivíduos e organizações, algum grau de capacidade de agência, ou seja, resposta estratégica a tais pressões (OLIVER, 1991). Diante disso, a noção de estratégia vem sendo reformulada para apoiar, de forma 
recursiva, as orientações institucionais. Como pode ser visto em Granovetter (1985) e em Whittington (1992), o comportamento econômico das pessoas varia de acordo com suas relações sociais imediatas ou mediatas, em que metas e processos estratégicos refletem os sistemas sociais nos quais a estratégia está sendo elaborada.

Em relação à atividade empreendedora, Aldrich e Fiol (1994) afirmam que os empreendedores enfrentam problemas, devido à ausência de legitimidade de seu novo negócio. Nesses casos, a legitimidade do empreendedor, e posteriormente a do negócio, são mediadoras entre a captação de recursos e a criação de riqueza (LOUNSBURY; GLYNN, 2001). Assim, como resultado de algumas pesquisas, se tem reconhecido a importância da legitimidade para o sucesso de novos negócios (ZIMMERMAN; ZEITZ, 2002). Em Rao (1994), verifica-se a preocupação em saber como é construída socialmente a reputação das organizações; já Barney e Hansen (1994) vêem a confiança como origem de vantagem competitiva; Lounsbury e Glynn (2001) acreditam que as histórias e o discurso do empreendedor servem para dar identidade e legitimar novos negócios e, em conseqüência, facilitam a captação de recursos.

Nessa linha de raciocínio, Zimmerman e Zeitz (2002) afirmam que a legitimidade tem papel-chave na criação, sobrevivência e no crescimento de novos negócios. Os autores argúem que a legitimidade é um recurso ${ }^{1}$, e o conceituam como julgamento social de aceitação, apropriação e desejo que permite às organizações acessarem outros recursos necessários à sua sobrevivência.

Nessa perspectiva, com o objetivo de compreender a construção da legit imidade organizacional, Hunt e Aldrich (1996) promoveram um modelo que inclui três tipos de legitimidade: sociopolítica regulatória; sociopolítica normativa; e cognitiva. Scott (2001) apresenta um modelo similar, incluindo três pilares do ambiente extemo, dos quais a legitimidade pode ser derivada: regulatória, normativa e cognitiva. Em adição aos três tipos de legitimidade sugeridos pelos autores, Zimmerman e Zeitz (2002), baseados em Aldrich e Fiol (1994), apresentam a legitimidade derivada da indústria em que o novo negócio opera, sendo sua classificação apresentada a seguir.

1) Legitim idade regulatória. A legit imidade regulatória (SCOTT, 2001), também conhecida como legitimidade sociopolítica regulatória (HUNT; ALDRICH, 1996), é oriunda de regulações, regras, padrões e expectativas criadas por governos, associações credenciadoras, agências reguladoras, associações profissionais e organizações influentes (ZIMMERMAN; ZEITZ, 2002). Normalmente, envolvem sanções a que as organizações devem atender, para que consigam legitimar suas ações (SCOTT, 2001). A legitimidade regulatória vai além de meras respostas às sanções. Envolve um senso generalizado de que o novo negócio opera de acordo com e no espírito das leis - um reconhecimento de que a organização é 'boa cidadã' (ZIMMERMAN; ZEITZ, 2002). A legitimidade regulatória pode ser instrumentalizada por meio do atendimento às leis, por meio do cumprimento de regras de agências regulatórias e certificadoras, entre outras formas. Para os novos negócios, não at ender aos requisitos regulatórios pode gerar diversos problemas, como dificuldade no acesso aos recursos e impossibilidade de regulamentação após algum tempo de atuação nessa situação irregular.

2) Legitimidade nomativa. A legit imidade normativa (SCOTT, 2001), também conhecida como legitimidade sociopolítica normativa (HUNT; ALDRICH, 1996), deriva das normas e valores da sociedade ou de ambiental social relevante para o novo negócio (ZIMMERMAN; ZEITZ, 2002). Uma organização é apropriada e desejada quando at ende a normas e valores, como ter lucrat ividade, respeitar os empregados e a comunidade, ser transparente com os financiadores, entre outros. Chave para uma nova organização acessar os recursos necessários é at ender a normas e valores daqueles que controlam tais recursos (ZIMMERMAN; ZEIT Z, 2002). Tal relação de confiança, entre os que necessitam e o que os detêm, só ocorre, se os que necessitam atendem aos ritos e cerimoniais exigidos pelos detentores. Porém existem algumas outras formas para que as novas organizações e o empreendedor possam acelerar esse processo. Uma forma é por meio do endosso - uma opinião favorável de outra organização, que serve como voto de confiança (RAO, 1994). Outra forma é por meio da rede de relações na qual o empreendedor buscará legit imidade e recursos (ALDRICH; FIOL, 1994).

3) Legitimidade cognitiva. A legitimidade cognitiva (SCOTT, 2001) origina-se de crenças e pressupostos que provêm um modelo de rotina diária, ou seja, conhecimento especializado e explícito, codificado como sistema de crenças promulgado por vários profissionais (SCOTT, 2001). O modelo cognitivo prevalecente prescreve a 
visão de mundo e como as ações são feitas. A legitimidade cognitiva indica qual é o 'jogo', a realidade socialmente construída pelos participantes (ZIMMERMAN; ZEITZ, 2002). Um novo negócio pode ser aceito pela implementação de métodos aceitos como úteis no domínio em que a organização opera (ALDRICH; FIOL, 1994; HUNT; ALDRICH, 1996; SCOTT, 2001; SUCHMAN, 1995). Um exemplo de legitimidade cognitiva é o pressuposto de que a qualidade do empreendedor é benéfica para o novo negócio.

4) Indústria como origem de legitimidade. Existe uma visão de que um tipo de indústria pode ter mais ou menos legitimidade, se comparada com outras. Um novo negócio pode usar os padrões da indústria (suas normas, práticas e tecnologia) e sua credibilidade para adquirir legitimidade (ALDRICH; FIOL, 1994; HUNT; ALDRICH, 1996; SCOTT, 2001; SUCHMAN, 1995). Indústrias podem apresentar vários graus de legitimidade, com base na variedade das ações e das conseqüências destas, que são refletidbs pelas ações colet ivas de seus membros. Nesses casos, um novo negócio pode aproveitar a legit imidade da indústria em que se insere para adquirir, com mais rapidez, recursos e legit imidade (ZIMMERMAN; ZEITZ, 2002).

Afirma-se, aqui, que a legitimidade é primordial para a aquisição de recursos e para a sobrevivência de novos empreendimentos. Desse modo, as organizações são passíveis de adotarem estratégias de ação que lhes conferem maior legitimidade, sejam elas legais, normativas, cognitivas ou industriais. Entretanto, a legitimidade não pode ser encarada como simples commodity (SCOTT, 2001), passível de manipulação pelo empreendedor. Apesar da capacidade de agência que o empreendedor possui, esta é limitada ou ampliada pelos entes relacionados ao seu negócio e à sua ação. Assim, suas ações repercutem conforme a interpretação dos membros que interagem com ele, diretamente ou não, dando a suas ações um caráter dinâmico próprio. Desse modo, defende-se que a tríade formada por relações, recursos e legitimidade possibilite maior compreensão da ação empreendedora em sua totalidade, uma vez que carece de arcabouço analítico para seu entendimento.

\section{Obtenção de legitimidade e recursos}

Como foi visto anteriormente, para que um novo negócio se desenvolva, necessita de recursos que o alavanquem (ALVAREZ; BUSENITZ, 2001). Assim, a reunião dos recursos, sua atração, sua combinação e sua transformação de recursos individuais em recursos organizacionais, é um desafio que o empreendedor tem de enfrentar para desenvolver seu negócio (BRUSH; GREENE; HART, 2002). No entanto as organizações, principalmente os novos negócios, precisam não somente de recursos materiais e informação técnica para se desenvolverem (SCOTT, 2001): necessitam, também, de legitimidade. Devido à ausência de legitimidade (ALDRICH; FIOL, 1994), os empreendedores passam por dificuldades em captar recursos e em criar riqueza (LOUNSBURY; GLYNN, 2001). Nesses casos, cabe ao empreendedor, por meio de suas ações, desenvolver uma rede de relações que possa proporcionar-lhe acesso a recursos e apresentar maior legitimidade. Ademais, no momento em que o empreendedor busca interação, fortalece as suas relações, institucionalizadas sob a marca da confiança e da adaptabilidade (PAIVA JÚNIOR; MELLO; GONÇALVES, 2005). Para Paiva Júnior, Mello e Gonçalves (2005, p. 161) “a confiança é prevalecente em qualquer estrato das alianças empreendedoras, enquanto premissa para a expansão do próprio empreendimento e da interação social do agente". Na construção de um empreendimento, o risco não é somente do empreendedor, mas também daqueles que assumiram algum tipo de compromisso com ele. 
Figura 2 - Arcabouço analítico da construção relacional de legitimidade e recursos

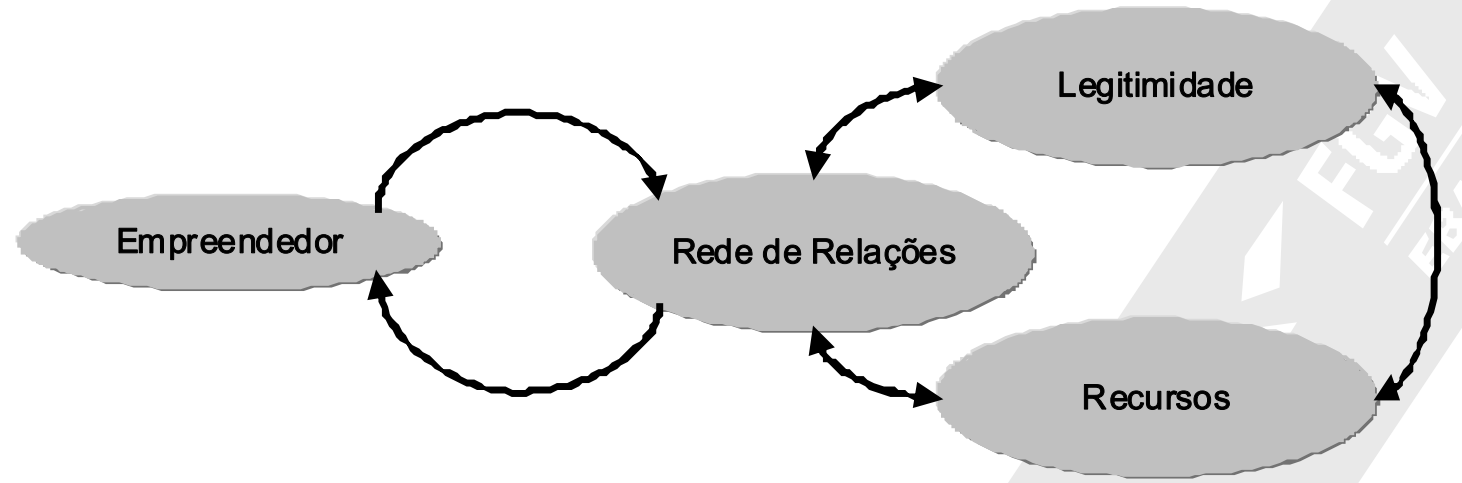

Na Figura 2 pode-se ver como ocorre a interação da rede de relações com os recursos e a legitimidade. Um empreendedor desprovido de recursos e sem histórico de resultados ou de credibilidade, em face dos entes relacionados, como única altemativa, tem de utilizar e construir uma rede de relações que lhe dê acesso aos recursos e the garanta a legitimidade necessária. Por meio de sua rede de relações, o empreendedor tem acesso aos recursos necessários para desenvolver o empreendimento. Essas relações são fortalecidas a partir do momento em que o empreendedor corresponde às normas estabelecidas, creditando legitimidade às suas ações. A legitimidade do empreendedor, representada pela confiança que os outros entes têm nele, e pelo seu compromisso em face das expectativas deles, pode ampliar a dimensão de sua rede de relações, facilitando o acesso aos recursos e reforçandb a legitimidade.

Nesse sentido, enquanto consegue manter um nível de legitimidade e enquanto suas ações não ferem os códigos vigentes de sua rede de relações, o empreendedor terá maior facilidade em acessar recursos. Contudo, a relação entre empreendedor, rede de relações, legitimidade e recursos é sempre recursiva: todos os elementos se retroalimentam. No caso de esse processo ser interrompido por algum motivo (por exemplo: pouca interação e uso da rede; não atendimento a nommas vigentes, como preceitos éticos, mau desempenho ou atitudes ilícitas; má aplicação de recursos, entre outros), o empreendedor, em vez de colher bons resultados, pode ter mais dificuldade em acessar recursos e novos contatos. Afinal, segundo Bernhoeft (1996), o fracasso dos empresários ocorre porque eles, muitas vezes, não levam em conta os aspectos fundamentais do compromisso que envolve uma at ividade empresarial.

Diante da necessidade de se operacionalizar o arcabouço analítico aqui apresentado, na seção seguinte serão expostos os procedimentos metodológicos utilizadb no presente caso.

\section{Enfoque metodológico}

O presente estudo tem como estratégia de pesquisa o estudo de caso. Essa estratégia é ideal quando se colocam questões do tipo 'como' e 'por que', e quando o foco é em fenômenos contemporâneos, em que não há definição clara sobre os limites entre fenômeno e contexto (YIN, 2001).

O tipo do caso foi o de único holístico, com a organização como única unidade de análise. Escolheu-se esse delineamento porque o presente caso satisfaz as condições para teste do arcabouço teórico e por este ser revelador. Elaborou-se uma questão de pesquisa, que foi desdobrada em um arcabouço analítico (Figura 2) posto como proposição a ser avaliada. Buscou-se com o arcabouço encontrar elementos para a generalização analítica dos elementos teóricos apresentados. Segundo Yin (2001), no método de generalização analítica, utiliza-se uma teoria previamente desenvolvida como modelo, com o qual se podem comparar os resultados empíricos do caso.

Em relação aos critérios de qualidade, os seguintes elementos foram examinados: a validade de construto, uso de múltiplas fontes de evidência, de encadeamento de evidências e revisão da minuta do caso pelos participantes; validade interna, por meio de construção de explanação; validade externa, somente no que se 
refere à generalização analítica; e confiabilidade, uso de protocolo de pesquisa e arquivo em banco de dados, de acordb com os procedimentos estabelecidos por Easterby-Smith, Thorpe e Lowe (1999) e Yin (2001). Antes da fase de coleta, foi elaborado um protocolo - importante para a confiabilidade do estudo - com todos os elementos indicadbs por Yin (2001).

As evidências foram coletadas por meio da análise de documentos da organização, de registros em arquivos, de entrevistas com o fundador, de observações diretas e de observação participante, pois o pesquisador atuou como voluntário da organização no período. Buscou-se a convergência das evidências mediante triangulação dos dados, com o objetivo de validar o construto. Todos os dados foram arquivados em banco de dados em meio eletrônico.

Procurando maior confiabilidade das informações, o encadeamento de evidências foi feito por meio da exposição dos relatos do fundador. Em relação à análise de evidências, selecionou-se a técnica de criação de matriz de categorias (Quadro 2), com estratégia geral baseada em proposição teórica (Figura 2).

Como método de análise, utilizou-se a construção de explanação, adequado quando se procura evidenciar as relações entre categorias analíticas. Os elementos extraídos da entrevista transcrita - expostos no Quadro 2 foram classificados e agrupadbs conforme sua relevância para as categorias analíticas e para os elementos de análise.

\section{Quadro 2 - Categorias analíticas e elementos de análise}

\begin{tabular}{ll}
\hline Categorias & Elementos \\
\hline 1. Rede de relações: Filion $(1991,1993)$ & $\begin{array}{l}\text { Relações primárias: familiares e amigos } \\
\text { Relações secundárias: pro fissionais, esportivas, sociais, políticas, } \\
\text { ideológicas } \\
\text { Relações terciá rias: cursos, viagens, feiras, livros. }\end{array}$ \\
\hline $\begin{array}{l}\text { 2. Recursos e desafios enf rentados: Brush, } \\
\text { Greene e Hart (2002) }\end{array}$ & $\begin{array}{l}\text { Tipos de Recursos: humano, social, financeiro, físico, tecnológico, } \\
\text { organizacional } \\
\text { Desafios: Reunião, Atração, Combinação e Transformação }\end{array}$ \\
\hline
\end{tabular}

3. Legitimidade: Hunt e Aldrich, (1996); Suchman (1995); Scott, (2001); Zimmerman e Zeitz (2002)

Tipos: legal, normativa, cognitiva, industrial

Por meio da categoria 'rede de relações’, objetivou-se descrever as relações primárias, secundárias e terciárias, segundo os critérios estabelecidos por Filion $(1991,1993)$. Já a categoria 'recursos’ refere-se tanto a como foram adquiridos, quanto aos desafios exigidos para sua aquisição. A classificação dos recursos e dos desafios seguiu a classificação de Brush, Greene e Hart (2002). Com a categoria 'legitimidade' busca-se apresentar como os empreendedores legitimaram o seu negócio, sendb utilizada a classificação de Zimmerman e Zeitz (2002) de origens da legitimidade.

\section{O caso da ONG Aliança Empreendedora}

A Aliança Empreendedora² é organização não govemamental, situada em Curitiba e atua no desenvolvimento de trabalho e renda para comunidades menos favorecidas, por meio do estímulo à criação de novos empreendimentos. Com uma filosofia de rede de relacionamentos, a Aliança Empreendedora oferece suporte, mediante grupo de voluntários formadb por estudantes de graduação e profissionais, para aqueles que querem criar um negócio, mas não sabem como. Os voluntários vêem como vantagem a possibilidade de aplicar seus conhecimentos de forma solidária. Por meio dessa rede de voluntários, a organização assessora tanto empreendedores em potencial a criar um empreendimento, quanto pequenos empresários com negócios em dificuldades. Primeiro, os empreendedores são selecionadbs em comunidades mais carentes, onde recebem as primeiras noções sobre empreendedorismo. Depois, quando já têm uma idéia formada a respeito de negócio, recebem assessoria dos voluntários, que os estimulam a elaborar um plano de negócios e a tomar ações em prol 
da criação ou do desenvolvimento de seus negócios. Além do trabalho de consultoria voluntária, a Aliança desenvolve programas de educação empreendedora, estimula a criação de centros do empreendedor nas comunidades e assessora outras ONGs em seu processo de gestão e de organização.

A organização se originou da extinção de outra organização não governamental, a Empreendedores dos Sonhos, formada em 2003, no Paraná, por alguns membros da Aliança Empreendedora - os motivos de tal mudança serão expostos no decorrer do texto. Em viitude de a história de ambas as organizações se confundirem, o relato e a análise do caso serão feitos a partir da constituição da organização Empreendedores dos Sonhos.

Todos os jovens fundadores da organização se conheceram nas empresas juniores da universidade em que estudavam. Ainda dentro da empresa júnior, esses jovens participaram de uma série de programas e eventos de cunho social, quando, então, começaram a se interessar pela área e a desenvolver importantes contatos. Em comum, eles compartilhavam de um desejo de desenvolver atividades que mantivessem um ambiente de aprendizagem contínua, que não os levasse a perder o interesse pelo trabalho, a exemplo de muitos exempresários juniores que iam para o mercadb de trabalho.

E daí quando saímos da empresa júnior, víamos muita gente boa que saia, que falava que o mundo lá fora era diferente... que não tem mais aquele ambiente de aprendizado... que na empresa júnior se trabalha dois anos sem receber, pelo aprendizado... Que lá não tem mais aquele negócio de você criar, que lá o estágio é de oito às seis, e você tem sua lista de tarefas. Víamos muita gente apagando... sabe? Gentemuito boa... E a gente resolveu que ia trabalhar junto, depois de empresa júnior.

No ensejo de atuar no mercado de forma diferente, os jovens buscaram várias possibilidades de negócios, sempre voltados para a mobilização social. Então, em meadbs de 2002, no encontro de empresas juniores de São Paulo, um dos fundadores, Rodrigo Brito, em uma das palestras, conheceu a organização Empreendedores dos Sonhos, que naquele momento só existia no Ceará. Pela semelhança com o projeto que estes jovens gostariam de desenvolver no Paraná e com a promessa de apoio de outras organizações, decidiram, então, criar a Empreendedores de Sonhos do Paraná. Durante o período de setembro de 2002 a junho de 2003 desenvolveram a metodologia de trabalho e buscaram parcerias para viabilizar o projeto de criação da ONG.

Das diversas tentativas e projetos idealizados, conseguiram viabilizar um projeto de incubadora social, por meio de recursos de parceiros e do apoio de voluntários. Esse período foi crucial para a organização, pois foi o momento em que ocorreram as maiores dificuldades. Além das incertezas existentes quanto a começar um projeto novo, sem metodblogias de trabalho, eram todos jovens e desconhecidos, o que dificultava o relacionamento com potenciais patrocinadores do projeto. No entanto, devido a algumas ações anteriores, como a realização bem sucedida de um grande evento - o Encontro Nacional das Empresas Juniores - os jovens tinham respaldo com algumas organizações que incentivaram esse encontro. Mesmo assim, algumas das promessas de apoio não foram cumpridas, o que os levou a desenvolver outras atividades para manter o funcionamento da ONG.

Concomitantemente com o desenvolvimento desse projeto, os jovens contribuíam para a formação da Empreendedores dos Sonhos em outros Estados, alcançandb a posição de coordenação nacional. Até 2004 havia bom relacionamento entre a Empreendedores dos Sonhos do Paraná e a do Ceará. Porém, alguns conflitos e divergências entre as duas entidades levaram ao rompimento da parceria. Segundo relato dos fundadores da entidade no Paraná, no decorrer do tempo, as metodologias de atuação das duas entidades foram se diferenciando, até porque, sendo recém-criadas, tinham de se adaptar de acordo com os recursos disponíveis. No entanto o principal motivador da separação, segundo membros da Empreendedores dos Sonhos do Paraná, foi a escolha de um de seus fundadores como líder $\mathrm{AVINA}^{3}$, que gerou mal-estar por parte dos fundadores do Ceará. No processo de escolha do líder AVINA, alguns fatos pesaram contra a Empreendedores dos Sonhos do Ceará: o perfil dos fundadores era mais político que executivo, e, entre eles, a maioria era de ativistas políticos. Além disso, muito do que a entidade do Ceará divulgava como realizações ainda não havia acontecido, gerando descrédito nas suas ações posteriores. Os jovens da Empreendedbres dos Sonhos do Paraná, ao contrário, apresentavam um perfil mais realizador, o que fortaleceu sua imagem perante os avaliadores da AVINA e levou um de seus fundadores a ser selecionadb. Em virtude desses fatos, ocorreu um rompimento entre as duas, que 
acarretou o fechamento da Empreendedores dos Sonhos do Paraná e deu origem, no início de 2005, à Aliança Empreendedora no Paraná.

As circunstâncias em que a Organização Aliança Empreendedora foi construída são excelentes para a análise do caso aqui exposto. A organização carecia de elementos primordiais à sua criação, como rede de relações, recursos e legitimidade. Por isso, é ideal no sentido de atender ao propósito do estudo, qual seja: analisar como empreendedores usam sua rede de relações para conseguir legitimidade e recursos no desenvolvimento da organização. Para isso os dados serão apresentados de acordo com as categorias analíticas escolhidas para o estudo: rede de relações, recursos, e legitimidade.

\section{Rede de relações}

Por serem jovens e por não terem experiência no terceiro setor, os fundadores da Aliança não tinham uma rede bem desenvolvida, o que os levou a buscar apoio em diversas organizações, como pode ser visto pelo depoimento: "A gente começou a buscar uma rede de parcerias de atuação e parcerias institucionais. Então a gente criou uma rede para dar credibilidade e força, antes de buscar qualquer recurso. A gente começou a ter certo envolvimento com a área do terceiro setor”.

Em relação à rede de relações primárias - ligada a família e amigos (FILION, 1991, 1993) -, observa-se forte relação de amizade entre os membros fundadores, que compartilhavam, muitas vezes, valores comuns: " $\mathrm{E}$ a gente conseguiu, nessa época, muitas pessoas amigas nossas, ex-empresários juniores, que tinham muito interesse em participar do projeto. Todo mundo é ex-empresário júnior, não tem uma trajetória, um perfil político".

Nem sempre os fundadores tiveram apoio dos familiares. Segundo um deles, houve resistência dos pais em aceitar que os filhos desenvolvessem atividades no terceiro setor, uma vez que poderiam ter melhores condições de trabalho no setor privadb.

Analisando a rede de relações secundárias (FILION, 1991, 1993), ou seja, entre conhecidos envolvidos em tomo de uma atividade profissional, verificou-se que, apesar de os fundadores não terem experiência profissional na área do terceiro setor, a essência da forma de atuação da organização fundamentou-se nas experiências anteriores:

A Empreendedores dos Sonhos nasceu em agosto de 2002, e todo esse grupo se conheceu em 2000 nas empresas juniores. Muito dessa cultura que há hoje na Aliança veio da época de empresa júnior.

Aparentemente, um dos pontos-chave no desenvolvimento do projeto foi a freqüente utilização dos contatos para desenvolver a maioria das atividades e, também, para a captação de recursos, como, por exemplo, o uso da rede de relações para conseguir espaço físico.Então a gente precisava de espaço físico... ocioso. Então a gente buscou parceria com a CIC, que tinha nove barracões vazios da união de emprego.

Pouco a pouco, outras parcerias foram criadas, garantindo não só recursos financeiros, mas uma série de contribuições. Há, também, uma constante interação com as diversas partes na rede, e a preocupação de sempre construir alguma forma de aprendizado. Tal fato contribui para o reconhecimento das at ividades do grupo.

(...) o Paraná criou a lista de e-groups, para fazer o acompanhamento dos outros estados. Nesse processo, com o a gente estava fortalecendo a empreendedores nacionalm ente, nacionalmente a gente era fortalecido.

No presente caso, a rede de relações terciárias (FILION, 1991, 1993), relacionada a cursos, feiras e eventos, foi também extremamente importante na descoberta da idéia, na formação de parcerias e no processo de construção da rede de relações secundárias.

Então a gente, ainda na empresa júnior, tinha organizado alguns projetos, um deles em que a gente participou foi o Sete Sigma, que é da Amana-Key, uma empresa de São Paulo, da área de gestão, que 
foi o concurso nacional. E o ENEJ, que eu comentei, foi o grande início dessa rede de contatos. Por exemplo, esse trabalho na FGV surgiu pelo nosso trabalho no ENEJ. E nesse trabalho do ISAE-FGV, eu fui para São Paulo fazer uma série de reuniões durante o encontro de empresas juniores de São Paulo. Aúnica palestra a que eu fui foi da Empreendedores dos Sonhos.

\section{Recursos}

As definições e a classificação dos recursos seguiram os parâmetros de recursos definidos por Brush, Greene e Hart (2002): humanos, sociais, financeiros, físicos, tecnológicos, e organizacionais. A Empreendedores dos Sonhos, que deu origem posteriormente à Aliança Empreendedora, teve alguns desafios relacionados a recursos humanos, como falta de experiência e de conhecimento: "Que é a dificuldade do fato de ser jovem, pelo fato de conhecimento... pelo fato de nunca ter trabalhado na área...”

Os recursos sociais, ligados aos contatos com o setor e com a credibilidade e reputação do grupo, foram bem desenvolvidbs no decorrer do tempo e são os de maior importância para o incremento de outros recursos da organização. Um dos próprios fundadores afirmou: “O principal ativo de uma ONG é sua reputação”. Alguns pontos são marcantes, como o reconhecimento da organização pelo Encontro Nacional de Empresas Juniores (ENEJ), que possibilitou uma série de contatos com outras organizações, e a seleção de líder AVINA qualificação de renome nacional. A participação em conselhos é também freqüente, que possibilita o aumento de representatividade da organização. Existe, atualmente, um maior reconhecimento quanto ao trabalho da Aliança: "Dos investidores, hoje em dia, a rede de pessoas, a rede de depoimentos, a rede de organizações em que estão envolvidas dá credibilidade, gera interesse”.

Como qualquer outra organização não governamental, os recursos financeiros geralmente vêm de pessoas não envolvidas diretamente ou por meio de empresas. No início, os fundadores não possuíam nenhum recurso para criar a organização e muitos necessit avam de desenvolver at ividades paralelas para se manterem. Entretanto, os contatos desenvolvidos e a reputação que o grupo já havia conseguido na organização do ENEJ facilitou o acesso aos recursos com o IEL, Instituto Euvaldo Lodi do Paraná, que havia sido anteriomente patrocinador do ENEJ. Sempre usando da rede, eles conseguiram captar os outros recursos necessários à criação da organização; o maior deles foi o investimento feito pela FAS, Fundação de Assistência Social da Prefeitura de Curitiba, para desenvolver a incubadora do Cajuru.

O IEL foi o grande patrocinador do ENEJ, e também o grande patrocinador do movim ento empresa júnior no Paraná. Então já tínhamos certo contato com o IEL, mas não um contato pessoal forte. Tinha um contato do resultado do ENEJ, que tinha sido muito bom. Então o IEL pagou quatro bolsas para essas pessoas, de junho a dezembro de 2003. E em agosto de 2003, a Prefeitura, a FAS, disse: "A gente vai pagar o projeto do Cajuru". E o IEL, perto de dezembro de 2003, afirmou: "Eu vou bancar o escritório e as dez pessoas no ano de 2004". Então tínhamos o projeto com a FAS, que era um projeto caro, cerca de $R \$ 150.000,00$, pra equipar todo o barracão, pagar segurança, telefone, luz, água, Internet, que era alto o valor de luz e telefone do barracão. O barracão tinha 700 metros. Tudo que era manutenção, instalação, éramos nós que fazíamos.

Os recursos tecnológicos necessários à organização podem ser divididos de duas formas: os referentes ao desenvolvimento da incubadora, que era especificamente formada por pequenas confecções; e os relacionadbs à organização em si. No primeiro caso, houve busca por apoio fora da organização.

A gente precisava de alguém que já tivesse amplo conhecimento de trabalho comunitário; então a gente fechou parceria com a FAS, que fazia o modelo colaborativo. Ai a gente queria alguém que focasse o desenvolvimento de produto. Então a gente fechou parceria com o Centro de Design do Paraná.

Na segunda situação, necessitava-se desenvolver a metodologia de trabalho, ou seja, processos de captação, seleção e preparação de empreendedores de forma que se alcançasse o melhor resultado possível. 
Os recursos organizacionais - mais relacionadbs ao processo de trabalho e de atuação da organização como um todo - desenvolveram-se no decorrer do tempo. O modelo mais colaborativo de gestão veio não somente da influência de trabalho, na empresa, dos fundadores, mas muito de tentativase erros oriundos de um processo de aprendizagem, em virtude de setratar de atividade consideravelmente nova e com processo diferenciado.

Muito do que hoje a gente está desenvolvendo, já para a próxima turma de empreendedores, foi de aprendizado, de erro e acerto do Cajuru. A gente sempre está estudando e refinando as nossas estratégias de captação de recursos. Isso... cada vez mais a gente está fortalecendo a área de comunicação para fazer isso.

Os desafios enfrentados na construção da base de recursos (BRUSH; GREENE; HART, 2002) foram continuamente contomados pela organização, o que explica, em parte, a sua sobrevivência. Em relação à atração dos recursos, os fundadores sempre utilizaram sua rede de contatos e projetos de captação. Já para a combinação dos recursos, os membros buscavam as potencialidades de cada um. Também dividiam o trabalho, focavam em metas, elaboravam controles e processos. Griaram, ainda, uma espécie de memória organizacional, fonte de aprendizado passado, para evitar erros no futuro. Por meio de reuniões freqüentes, procuraram melhorar a interação das diversas ações dos membros. Quanto à transformação de recursos individuais em recursos organizacionais, os membros seguiram, basicamente, a diretriz de transformar processos em metodblogia.

\section{Legitimidade}

Para analisar o desenvolvimento da legitimidade da organização, foram utilizadas as definições de Zimmerman e Zeitz (2002), que adaptaram alguns elementos de Hunt e Aldrich (1996) e de Scott (2001), como a legitimidade regulatória, normativa, cognitiva e de origem da indústria. Primeiramente, em relação à legitimidade regulatória, que vem db atendimento a leis, regras e normas estabelecidas formalmente e do reconhecimento de que a organização opera de acordo com as leis, a Aliança Empreendedora atendeu, sem exceção, aos requisitos necessários. Muitos dos benefícios e dos recursos só foram obtidbs por se tratar de uma ONG com premogat ivas legais para receber doações de órgãos públicos e empresas privadas.

No que tange à legitimidade normativa, derivada do atendimento às normas e aos valores da sociedade ou do ambiente social relevante, a Aliança Empreendedora conseguiu desenvolver-se devido ao fato de ter atendido a essas normas. No início, sem reconhecimento social: "Que é a dificuldade do fato de ser jovem, pelo fato de conhecimento, pelo fato de não ter recurso, pelo fato de nunca ter trabalhado na área. Isso aí afetou a legitimidade. No início não existia legitimidade; foi sendo construída”. № entanto, os parceiros aureditaram nos jovens em razão de alguns resultadbs alcançadbs em experiências anteriores, o que facilitou a construção da legitimidade.

Então a gente foi a única equipe jovem que participou; das cento e oitenta, treze foram selecionadas, $e$ dessas treze, a nossa equipe e mais uma foram as que tiveram o maior quesito. (no Projeto Sete Sigma).

Então já tinha certo contato com o IEL, mas não pessoal forte; tinha um contato do resultado do ENEJ que tinha sido muito bom.

Ao longo do tempo de atuação, o bom trabalho da organização tanto fortaleceu a legitimidade quanto facilitou o acesso a recursos.

O Paraná é selecionado líder AVINA, que é algo de representação, de representatividade internacional. Então as empresas estão marcando reunião. Isso já é uma vitória. No começo era mais um a ONG nova. Hoje em dia, todo o mundo já conhece, já sabe que tem o trabalho, então é... eles vêem que já tem uma solidez na atuação, na tradição. Dos investidores, hoje em dia, a rede de pessoas, a rede de depoimentos, a rede de organizações em que estão envolvidas dá credibilidade, gera interesse... os resultados já gerados. 
Valores como lucratividade, tangibilidade, pragmatismo, eficiência e eficácia estão presentes no dia-a-dia das organizações não govemamentais. O fato de a Aliança Empreendedora conseguir demonstrar tais indicadbres fortaleceua imagem de organização séria.

Em janeiro de 2005 nós tínhamos o que chamamos de nova metodologia, para reduzir custo, ampliar etapas, melhorar processo, melhorar resultados. Ela é uma causa que ela não é tão comovente, mas ela é extremamente necessária e com resultados extremamente tangíveis e interessantes, transformadores. Por exemplo, o resultado de uma ONG de cultura émuito intangível. Então, às vezes, isso gera dificuldade. No caso da Aliança, no caso do empreendedorismo, é muito mais "tangibilizável” isso.

Em relação à legitimidade cognitiva, que pode derivar das crenças e pressupostos que provêm um modelo de rotina diária, um conhecimento especializado e codificado, verificarse que houve preocupação constante dos membros da Aliança em implementar modelos, práticas e processos úteis e desejados no domínio em que operam.

Então o Paraná criou 'Como que se monta uma Empreendedores dos Sonhos', Folha tarefa, modelo de plano de negócios, nunca teve, sabe? E a gente começou aos poucos, desenvolvendo todos esses processos, metodologias e passar para a lista nacional. A gente trabalha sempre no desenvolvimento de um projeto muito consistente. A gente sempre está estudando e refinando as nossas estratégias de captação de recursos.

O fato de serem universitários e graduados, na maioria dos casos, em cursos da área de gestão, facilitou o desenvolvimento dessas rotinas e contribuiu para um maior entendimento das crenças compartilhadas entre os meios profissionais e empresariais.

E em relação à legitimidade originada da indústria, ou seja, da credibilidade proporcionada pelo tipo de indústria em que a organização atua, a Aliança beneficiou-se por ser uma ONG com boa visibilidade, atualmente, no meio público, e grande parcela de credibilidade. Muito do que a organização conquistou deveuse à boa imagem desse tipo de organização: "Por um lado, ajudou bastante, porque, por exemplo, se a gente fosse uma empresa, a prefeitura provavelmente não autorizaria todo o recurso e o incentivo que fez. Como é uma organização social, toda a questão é da transparência e dos objetivos”.

Pode-se observar que a construção da legitimidade da organização como um todo foi primordial tanto para o acesso aos recursos, quanto para o fortalecimento dos laços entre a rede de relacionamento. Se a Aliança não tivesse dado a devida atenção aos aspectos regulatórios, nomativos e cognitivos, provavelmente não teria se desenvolvidb.

\section{Conclusões}

Algumas conclusões merecem destaque no caso estudado. Pode-se observar que os membros fundadores da Aliança Empreendedora usaram fortemente a sua rede de relações e buscaram freqüentemente a sua ampliação. Essa at it ude, por si só, contribuiu para a aquisição de recursos e obtenção de legit imidade. Se os fundadores não tivessem comportamento proativo perante a rede, sem buscar reforçar constantemente os contatos e zelar pela manutenção dos valores respeitados pelos agentes da rede, provavelmente os resultadbs não seriam os mesmos.

A aquisição de recursos foi influenciada tanto pela ampliação e utilização da rede quanto pela legitimidade que os membros e a organização conseguiram no seu meio de interação. Sem atender aos elementos relacionados ao ganho de legitimidade, a resposta da utilização da rede provavelmente teria sido negativa. A legitimidade dos membros e da organização foi reforçada pelas ações dos membros. A transparência, abertura e ética dos membros em relação a sua rede fortaleceram os laços com os parceiros. Verificou-se forte relação entre as ações dos empreendedores, a sua rede de relações, a aquisição de recursos e a obtenção de legitimidade, dando respaldb e plausibilidade ao propósito db estudo. 
Com efeito, analisandb o processo de criação da Aliança Empreendedora, verifica-se que a decisão de seus fundadores em investir de forma consistente na formação de parcerias, estabelecendo rede de relações, propiciou a captação de recursos que, por sua vez, oriou condições para a busca de legitimidade, sendo resultadb não apenas de parcerias, mas também das ações que os fundadbres tomaram. Ao mesmo tempo, o significado de tais ações contribuiu para o aumento da legitimidade, facilitando o acesso a recursos. Portanto verificou-se que o arcabouço teórico analítico adbtado no estudo foi válido, havendo forte dinâmica entre o empreendedor e sua rede de relações na aquisição de recursos e legitimidade.

Tendo em vista a interdependência das bases relacionais do empreendedor com o aumento da legitimidade e com a aquisição de recursos, observa-se que, em conjunto, tais elementos são importantes para a compreensão do desempenho diferenciado de algumas organizações. Nesse caso, vem sendo amplamente discutido o papel da imersão social - que compreende tanto os aspectos relacionais quanto a questão da legitimidade - no desempenho das organizações (para uma revisão sobre imersão, ver Krippner e Alvarez, 2007). Nessa perspectiva, aquelas organizações que estão imersas socialmente tendem a apresentar melhor desempenho, sendo esse o caso da Aliança Empreendedora. No ent anto dificilmente tais resultados poderiam ser averiguados por meio de medidas de desempenho convencionais, principalmente as econômicas, pois organizações sociais apresentam diferentes critérios de avaliação. Como ressalta Meyer (1994), medidas de desempenho comumente utilizadas na perspediva econômica não são factíveis de uso em diversos tipos de organizações. Assim, o desempenho de organizações sociais foi avaliado por muito tempo no âmbito da sociologia, com foco na eficácia organizacional. Na análise sociológica, medidas de desempenho são vistas como construções sociais, se questionando, sempre, não só os oritérios de avaliação em si, mas para quem são feitos e até quando são válidos. Nessas condições, acredita-se que o estudo dos aspectos ligados às relações, aos recursos e à legitimidade sejam válidos para entender por que algumas organizações são bens sucedidas e outras não.

Para futuras pesquisas, propõe-se a utilização de estudos de múltiplos casos, bem como a comparação com outras organizações que não obtiveram sucesso. Outra sugestão é a de realização de pesquisas quantitativas, utilizando-se variáveis operacionais e indicadores baseados nos estudos qualitativos, buscando relações de tais elementos com o desempenho organizacional. 


\section{Referências Bibliográficas}

ALDRICH, H.; FIOL, C. M. Fools rush in? The institutional context of industry creation. Academy of Management Review, v. 19, $n$. 4, p. 645-670, 1994.

ALVAREZ, A. S.; BUSENITZ, L.W.The entrepreneurship of resource-based theory.Journal of Management, v. 27, p. 755-77, 2001. AMIT, R.;SCHOEMAKER, P. J. Strategic Assets and Organizational Rent. Strategic Management Journal, v. 14, p. 33-46, 1993.

ARBAUGH, J.; CAMP, M; VORHIES, D. Managing growth transactions immerging firms: a conceptual integration of resource, knowledge and life cycle theory. In: Academy of Management Annual Meeting, 1999, Chicago. Anais... Chicago: Academy of Management, 1999.

BARNEY, J.Firm Resources and Sustained Competitiv e Adv antage. Journal of Management, v. 17, n. 1, p. 99-120, 1991.

. Gaining and sustaining competitive advantage. Reading: Adisson Wesley, 1996.

BARNEY, J.; HANSEN, M. A. Trustworthiness as a Source of Competitiv e Advantage. Strategic Management Journal, v. 15, Special Issue, p. 175-190, W inter 1994.

BERNHOEFT, R.Como tornar-se empreendedor em qual quer idade. São Paulo: Nobel, 1996.

BRUSH, C. G.; GREENE, P. G.; HART, M. M. Empreendedorismo e construção da base de recursos. RAE - Revista de Administração de Empresas, São Paulo, v. 42, n. 1, p. 20-35, jan./mar. 2002.

BRUYAT, C; JULIEN, P. A. Defining the field of research in entrepreneurship. Journal of Business Venturing, v . 16, n. 2, p. 165$180,2001$.

BURT, R. S. Structural Holes: The Social Structure of Competition. Cambridge, MA:Han ard Univ ersity Press, 1992.

CANTILLON, R. Essai sur la nature du commerce en general. London: Fetcher Gyler, 1755.

CHANDLER, G; HANKS, S. H. Market attractiv eness, resource-based capabilities, venture strategies and venture performance. Journal of Business Venturing, v. 9, n. 4, p. 331-349, 1994.

CHATTERJEE, S.; WERNERFELT, B. The Link Between Resources and Type of Diversification: Theory and Evidence. Strategic Management Journal,v.12, p. 33-48, 1991.

COLLIS, D. J.; MONTGOMERY, C. A. Competing on Resources: Strategy in the 1990s. Harvard Business Review, p. 118-128, July/Aug. 1995.

CRUBELLATE, J. M.; PASCUCCI, L.; GRAVE, P. S. Visão baseada em recursos legítimos: recursos e padrões institucionais na formulação de estratégia em organizações. In: 3ES, Encontro de Estudos em Estratégia, 2005, Rio de Janeiro. Anais... Rio de Janeiro: ANPAD, 2005.

DANJOU, I. L'entrepreneuriat: un champ fertile à la recherche de son unité. Revue Française de Gestion, n. 138, p. 109-125, 2002.

DIMAGGIO, P. Interest and agency in institutional theory. In: ZUCKER, L. (Ed.) Institutional Patterns and organizations: culture and env ironment. Cambridge: Ballinger, p. 3-21, 1988.

EASTERBY-SMITH, M; THORPE, R.; LOWE, A.Pesquisa Gerencial em Administração. São Paulo: Pioneira, 1999.

FILION, L. J. Diferenças entre sistemas gerenciais de empreendedores e operadores de pequenos negócios. RAE - Revista de Administração de Empresas, São Paulo, v. 39, n. 4, p. 6-20, Out./Dez. 1999.

. Visão e relações: elementos para um metamodelo empreendedor. RAE-Revista de Administração de Empresas, São Paulo, v. 33, n. 6, p. 50-61, Nov./Dez. 1993.

.O Planejamento do seu sistema de aprendizagem empresarial: identifique umav isãoe av alie o seu sistema de relações.

RAE- Revista de Administraçãode Empresas, São Paulo, v. 31, n. 3, p. 63-71, Jul./Set. 1991. 
FOSS, N. R. Resource's firms and strategies: A reader in the resource-based perspective. Oxford: Oxford University Press, 1997.

GARTNER, W. B. A framework for describing the phenomenon of new venture creation. Academy of Management Review, . 10, p. 696-706, 1985.

GIDDENS, A. A constituição da sociedade. São Paulo: Martins Fontes, 1989.

GRANOVETTER, M. R. Economic Action and Social Structure:The Problem of Embeddedness, American Journal of Sociology, v. 91, p. 481-510, 1985.

GRANT, R. M. The Resource-Based Theory of Competitive Advantage: Implications for Strategy for Strategy Formulation. California Management Review, v. 33, n. 3, p. 114-135, 1991.

GUIMARÃES, T. B. C. Análise Epistemológica do Campo do Empreendedorismo. In: XXVIII ENANPAD, 2004, Curitiba. Anais... Rio de Janeiro: ANPAD, 2004.

HUNT, C. S.; ALDRICH, H. E. Why even Rodney Dangerfield has a home page: Legitimizing the world wide web as a medium for commercial endeav ors. In: Academy of Management Annual Meeting, 1996, Cincinnati. Anais... Cincinnati: Academy of Management, 1996.

KETS DE VRIES, M.F. R. The dark side of entrepreneurship. Harvard B usiness Review, p. 160-167, Nov./Dec 1985.

KRIPPNER, G. R.; ALVAREZ, A. S. Embeddedness and the Intellectual Projects of Economic Sociology. Annual Review of Sociology, v. 33, p. 219-240,2007.

LORRAIN, J.; DUSSAULT, L. Les entrepreneurs artisans et opportunists: une comparaison de leurs comportements de gestion. Revue International PME, v. 1, n. 2, p. 157-176, 1988.

LOUNSBURY, M; GLYNN, M. A. Cultural Entrepreneurship: Stories, Legitimacy, and The Acquisition of Resources. Strategic Management Journal,v.22, n. 6/7, p. 545-564, June/July, 2001.

MCCLELLAND, D. C. Entrepreneurship and achiev ement motivation: approaches to the science of socio-economic development. In: LENGYEL, P.Paris, UNESCO, 1971.

The achieving society. Princeton, NJ: Van Nostrand, 1961.

MEYER, M. W. Measuring Performance in Economic Organizations. In: SMELSER, N. J.; SWEDBERG, R. The Handbook of Economic Sociology. New Jersey: Princeton University Press, 1994.

NOHRIA. N. Introductions: Is a network perspective a useful way of studying organization. In: NOHRIA, N.; ECCLES, RG. (Eds.). Networks and Organizations. Boston, MA: Hav ard Businees School Press, 1992. p. 1-22.

OLIVER, C. Sustainable Competitive Adv antage: Combining Institutional and Resource-Based Views. Strategic Management Journal,v. 18, p.697-713, 1997.

.Strategic responses to institutional processes. Academy of Management Review, v. 16, n. 1, p. 145-179, 1991.

PAIVA JÚNIOR, F. G.; MELLO, S. C. B.; GONÇALVES, C. A. Empreendedorismo e relacionamento: um composto de confiança e adapt abilid ade In: EGEPE, 4., 2005, Curitiba. Anais... Curitiba, p. 159-168, 2005.

PENROSE, E.T. The Theory of the Growth of the Firm New York: John Wiley, 1959.

$\mathrm{RAO}, \mathrm{H}$. The Social Construction of Reputation: certification, contests, legitimation, and the surv $\mathrm{v}$ al of organizations in the American automobile industry: 1895-1912. Strategic Management Journal, v. 15, Special Issue, p. 29-44, Winter 1994.

SAY, J. B. Treatise on political economy: on the production, distribution and consumption of wealth. New York: Kelley, 1964.

. England and the English People. 2.ed. London: Sherwood, 1816.

SCHUMPETER, J. A. The theory of economic development. Cambridge: Han ard Univ ersity Press, 1934.

SCOTT, W. R. Institutions and Organizations. 2. ed. London: Sage Publications, 2001. 
SHANE, S; VENKATARAMAN, S. The promise of entrepreneurship as a field of research. Academy of ManagementReview, v.25, n. 1, p. 217-226, 2000.

SPANOS, Y.E.; LIOUKAS, S. An Examination into the Causal Logic of Rent Generation: Contrasting Porter's Competitiv e Strategy Framework and the Resource Based Perspective. Strategic Management Journal, v. 22, p. 907-934, 2001.

SUCHMAN, M. Managing legitimacy: strategic and institutional approaches. Academy of Management Review, v. 20, n. 3, p. $571-610,1995$.

TIMMONS, J. A. Black is beautiful - is it bountiful? Harvard Business Review, p.81-94, Nov./Dec. 1971.

VENKATARAMAN, S. The distinctive domain of entrepreneurship research: an editor's perspective. In: KATZ, J.; BROCKHAUS, R. (Eds.). Advances in entrepreneur ship research, firm emergence and growth. Greenwich: JAI Press, 1997.

VÉRIN, H. Entrepreneurs, enter prises, histoire dune idée. Paris: Presses Univ ersitaires de France, 1982.

VERSTRAETE, T.Entrepreneuriat-Connaître l'entrepreneur,comprender ses ac tes. Paris: Éditions L' Harmattan, 1999.

WEBER, M. The Protestant Éthic and The Spirit of Capitalism. London: Allen \& Unwin, 1930.

WERNERFELT, B. A Resource-Based View of the Firm, Strategic Management Journal, v.5, p. 171-180, 1984.

W HITINGTON, R. Putting Giddens into action: social systems and managerial agency. Journal of Management Studies, v. 29, p. 693-712, 1992.

YIN, R. K. Estudode Caso: Planejamentoe Métodos. Porto Alegre: Bookman, 2001.

ZIMMERMAN, M. A; ZEITZ, G. J. Beyond Survival: Achieving New Venture Growth By Building Legitimacy. Academy of Management Review, v. 27, n. 3.p. 414-431,2002.

\footnotetext{
${ }^{1}$ Mesmo sendo o agente capaz de tomar ações que possam ser consideradas legítimas, o autor não compartilha da idéia de que a legitimidade possa ser tratada meramente como recurso de firmas.

${ }^{2}$ O site institucional da organização é uwww. aliancaempreendedora. org.br.

${ }^{3}$ AVINA é uma entidade não governamental internacional que apóia e reconhece o trabalho de pessoas engajadas em projetos sociais seu certificado é reconhecido internacional mente. Além de ajuda financ eira, ser líder AVINA at esta a capacidade individual e idoneidade do escolhido, auferindo-Ihe credibilidade, já que o proc esso de seleção é extremamente longo e rig oroso.
} 